\title{
Pragmatic Analysis of Verbal Humors from the Perspective of Address Forms
}

\author{
Yan $\mathrm{Xu}$ \\ Foreign Language School \\ Huanghe Science and Technology College \\ Zhengzhou, China
}

\begin{abstract}
Actually, Address forms play an essential role in the interpretation of the verbal humors. From the angle of pragmatics, address is also a speech act. Based on the speech act theory, the speech act of address in a contextual use of proper address forms is to express some feelings or achieve some goals. Therefore, this article is devoted specifically to the pragmatic analysis of verbal humors from the perspective of address forms.
\end{abstract}

Keywords-verbal humor; address forms; pragmatic ambiguity; implication on teaching

\section{INTERPRETATION OF VERBAL HUMOR}

The term humor didn't enter the field of comic until the late $16^{\text {th }}$ century. Originally, humor meant liquid or fluid in Latin. Then, in medical language, humor was a term denoting body fluids, primarily blood, phlegm, black bile, and yellow bile. Up till now, humor has evolved into a kind of philosophical life attitude and positive coping device for frailty and imperfection of the world and human nature instead of pure mockery and irony.

In the Language Humor (1998: 7-8), Ross states that "the context for humor is crucial for determining whether an individual finds something amusing or not", and he generalizes the most obvious linguistic feature of much humor as an ambiguity, or double meanings, which deliberately mislead us to a particular interpretation. Basically, humor, as an effective laughter-generator, makes things amusing. However, humor is not only rendered for the shaping of a good temperament, display of amusement and the consolidation of social relationships, but also against adverse situations, such as nervousness, pain, anger, and even fear. Psychologically, humor is considered as a moderator of life stress and can enhance one's self-esteem and feelings of competence in the face of external treat (Martin, 1998:41). Mindess (1971) also noted that our social roles require us to suppress and deny many of our impulses and desires and to conform to our surroundings and the expectations placed on us by others. Meanwhile, humor offers us a temporary way of escaping from the life constraints and allows us to gain a sense of freedom.

However, there is a large diversity of classification methods of humor. Therefore, it is adopted from Bergson (1911) who divides humor into situational and verbal. While situational humor encloses the situational context into its formation, verbal or language humor is organized through verbal form. In other words, verbal humor is the humor created or expressed through language with the assistance of situational context occasionally.

\section{DEFINITION OF ADDRESS FORMS}

Address form is frequently used in daily interactions, to define it, however, is not an easy task because it involves many aspects.

- Address form is the word or words used to address somebody, in speech or writing. (Richard et al, 1985:4)

- Address forms are the words speakers use to designate the person they are talking to while they are talking to them. (Fasold, 1990:1)

- An address form is a numerically and attitudinallymarked designator which (a) functions as a particle to pronominal "you" to form a notionally paradigmatic phrasal "you"; (b) consist of names, words or a combination of both; (c) is used for the benefic of a speaker, addressee or a third-party hearer either optionally or necessarily for grammatical, practical, social, emotional or externally-imposed reasons. (Dunkling, 1990:22)

To sum up, an address form is the word or the words used to address a person directly in speech or writing to indicate interpersonal relationships separated in speech from the rest of the utterance by its own intonation contour.

\section{COMPARATIVE ANALYSIS OF ADDRESS FORMS BETWEEN ENGLISH AND CHINESE}

On the one hand, there exists similarity in address forms between English and Chinese. The first person pronoun, the second person pronoun and the third person pronoun are included in English and Chinese. Both of them have the single and plural forms, such as I/we/you/he/she/they in English, 我 (wo)、我们 (wo men)、你 (ni)、你们 (ni men)、他 (ta)、他们 (ta men) in Chinese. Besides , as for terms of respect, Chinese includes 老 + 姓 (Lao+family name）,such as 老李（Lao Li）,or 姓+老（family 
name+Lao） such as 圣老(Sheng Lao). Sometimes, 先生 (Sir) and 女士 (Lady) are called to refer to the persons who are respected in china. While Sir, Lady and Lord are terms of respect in English.

On the other hand, the difference between English and Chinese is that Chinese always respect the person who is the senior or at the higher position in the society. Therefore, “您” (nin) is utilized to reflect the loyalty to them. But, there are no corresponding words in English. In addition, as for the social relationship, Chinese is so complicated that there are two categories. One is the person pronoun that means that the speaker respects the addressee, for example, 贵 (gui), 贵 驾 (gui jia), 贵府 (gui fu), 贵夫人 (gui fu ren), 阁下 (ge xia). Another is the person pronoun in which the speakers belittle themselves, such as 鄙 (bi), 鄙校 (bi xiao), 鄙国 (bi guo), 鄙人 (bi ren), 犬子 (quan zi). Therefore, Chinese is the language of following the rule of humbling themselves. The speakers humble themselves and raise the reputation of the audience. There are only "You Majesty" and "Your Excellency" in modern English (He zhaoxiong, 2002). There is no person pronoun that humbles themselves and the system of person deixis is simple in English.

Meanwhile, the different cultures between China and America lead up to the various ways of address forms. It is prevalent for Americans to address First name when they get to know each other. While it is a rare phenomenon that Chinese address the person whom they get to know with First name, which is regarded as breaking the social norms in Chinese culture. For instance, a young woman, named Wang chunli, is familiar with a young man, called Zhao zuping. If the young woman addresses the man with Zuping, or the man addresses the woman with Chunli, the others will regard that the relationship between them is intimate and they are likely to be lovers. By contrast, if an American male addresses Wang chunli with Chunli, the Chinese female will feel embarrassed. Therefore, it is not proper for Americans to address the person, especially the Chinese female, with First name.

\section{PRAGMATIC ANALYSIS OF ADDRESS FORMS}

\section{A. Theory of Pragmatic Ambiguity}

Ambiguity is an expression whose meaning cannot be determined from its context and its unclearness arising from having more than one meaning. Also, the concept of ambiguity is vague in words and structures.

The uncertainty of linguistic phenomena that has no clear-cut distinction between truth and falsity is termed here as pragmatic vagueness from the perspective of pragmatics. In daily conversation no one speaks without fuzziness, generality, approximation, ambiguity, ambivalence. It is said we come across one of those phenomena in our speech once in every 15 seconds.

\section{B. Pragmatic Analysis}

Address forms, as an impressible linguistic phenomenon, have always been the object of sociolinguistic researches.
From the angle of pragmatics, address is also a speech act. Basing on the speech act theory, the speech act of address in a contextual use of proper address forms is to express some feelings or achieve some goals. In daily communication, under the influence of setting, emotion and role relationship of the interlocutors as well as the selection of topic, the address form used to address the same person will be changed; at the same time, the change of address forms to one person can also alter topic, atmosphere in communication, adjust interpersonal relationships and rebuild the current situation, thus the social psychological motivation of the speaker can be achieved.

In the course of interpretation of verbal humor, address form is a rich source for humor formation. We start fist from an example with ambiguity on address forms.

1) A father is trying to get his 3-year-old daughter to stop lifting up her dress to display her new underwear to the assembled guests.

Father: We do not do that.

Daughter: I know, Daddy. You don't wear dresses. (Peccei, 2000: 1)

The little girl explained why her father was not participating in the underwear show with perfect grammar and quite impeccable logic. The problem is that she appears to have understood what the words meant but not what her father meant (Ibid.). In other words, the little girl is linguistically competent, however, not pragmatically competent. For in English, the pronoun 'we' allows several different interpretations. The most commonly used 'we' is an exclusive 'we' referring the speaker plus others but excluding the addressee. Linguistically, this can be differentiated by the use of 'Let us' or 'Let's', or in other cases, this ambiguity could be easily resolved by the assistance of context.

Meanwhile, there is a third kind of usage for 'we', which seems to be more complicated, especially for a kid of 3 -year-old to master. This rule is that 'we', under some circumstances, refers to the addressee only and the father actually intended to mean this. Apparently, the little girl hasn't acquired this pragmatic rule and it is just unconscious rule breaking that constitutes the incongruity which is so valued by the humor.

Now, let's see another 'we' joke to testify further the ambiguity possibilities created by the mismatch of address form and their intended referents in the physical surroundings.

2) Television newscasters are always trying to segue cleverly from one segment of the news to another. During a newscast in the Midwest, a female anchor reported on a harsh winter storm, then turned to the weatherman and asked, "Well, will we need two blankets tonight?" To her surprise, he quickly replied, "what do you mean 'we'?"(Zhang 2000:192)

Once again, here different interpretations of 'we' get collided here. For the female anchor, the 'we' is used in its most general sense referring to all the audience watching the newscast or even all the residents living in the Midwest, 
however, in the understanding of the weatherman, 'we' exclusively refers to the anchor and himself with all the possible implications thereafter. The word 'we' is a small word, but it can make great 'trouble' and great humor.

3) A friend of mine was giving an important dinner party for her husband's business associates. She put guest towels and soap in the bathroom, and not wanting her teenagers to use them first, attached warning notes that read: "Use these and I'll kill you!". When the guests left after a successful evening, she went into the bathroom and found the towels and soap untouched-with her warning notes still in them. (Zhang 2000:133)

Apparently, the young mother attached the warning note with just a single thought of reserving the towels and soap exclusively for the guests for fear that her teenagers would spoil them. However, her good intention conveys false and misleading information. When the guests really read the notes before using the towels and soap, because the person pronoun 'you' is such a general deixis that can be used to refer to everybody who reads the note which includes the teenagers and the guests equally, i.e. the specific referent of 'you' relies on the specific context. Therefore, due to the ambiguities and uncertainties of the referent target, the warning note sounds so appalling that no one dared to even touch the towels and soap at the risk of losing his or her life. When such a kind warning is received so seriously, the laughter of our readers is easily elicited.

Besides the person pronouns in address forms, the vocatives are also included in the address forms, such as name, title, honorific, etc. Misunderstandings of this kind of can also lead to verbal humor.

4) Bill: "Well, what did she say when you proposed to her?"

Jim: "I didn't propose. Before I got a chance she told me she loved Emerson, Longfellow and Poe, and what chance did I have with a girl who is in love with three other fellows?"(Qun, 1985)

Firstly, this joke concerns a problem of names and referents. Yule has stated that there is a convention in our language community that certain referring expressions will be used to identify certain entities on a regular basis (2000:19), such as 'Shakespeare' only used to identify one specific person who wrote the play Romeo and Juliet. On the same basis, Emerson, Longfellow and Poe refer specifically to the writers and poets whom the girl admired instead of three fellows named Emerson, Longfellow and Poe whom the girl was in love with. Unfortunately, Jim ignorant of this most basic common sense knowledge and even took them for his love enemies. If it is true, it turns out to be a piece of humor with bitter taste.

Meanwhile, possessive pronoun shows a similar tendency for creating ambiguity as address form.

5) A melamed, discovering that he had his comfortable slippers back in the house, sent a student after them with a note for his wife. The note read: "send me your slippers with this boy." When the student asked why he had written "your" slipper, the melamed answered: “Fool! If I wrote 'my' slippers, she would read 'my' slippers and would send her slippers. What could I do with her slippers? So I wrote 'your' slippers, she'll read 'your' slippers and send me mine." (Levinson, 1983:68)

Here, the ambiguity about 'my slippers' or 'your slippers' is not only a problem for a correct judgment on the narration voice but also a pragmatic failure in references. Therefore, the acquaintance of the pragmatic rules about the reference under the changed reading and listening perspectives from those of speaking is really a gradual process during which any kind of confusion would lead easily to humor.

6) The needs of senior citizens and the disabled should draw the public's attention.

'Senior citizens' and 'the disabled', being the euphemistic way of speaking in people's daily life, refer to the old people and the paralyzed respectively. It is well known that foreigners' distinctive characters are humorous, frank and implicit, which contributes to their language features with humor, exaggeration and implication. When people describe somebody who is very old, they always express the meanings indirectly.

\section{7) Scene 1}

A: Could you please tell us how late your store is open this evening?

\section{B: Ma'am?}

A: Could you please tell us how late your store is open this evening?

\section{B: Until eight.}

Scene 2

A: Could you please tell us how late your store is open this evening?

\section{B: Until eight.}

A: Thank you very much.

B: Yes, ma'am.

Ma'am, being employed in the two scenes, has different meanings in different contexts. In scene 1, Ma'am refers to "I beg your pardon", while ma' am in scene 2 means "You are welcome". These two examples indicate that the address form has various implications in different language background in America. In general, foreign language cultures should be emphasized in the process of learning language and foreign language teacher should develop and cultivate learners' sensitiveness of cultural difference which contributes to the differences of address forms between Chinese and English.

\section{IMPLICATION ON FUTURE TEACHING}

Based on pragmatic analysis above, there are many different address forms, resulting from the different cultures between Chinese and English, which are obstacles for Chinese learners. For example, many students always address foreign teachers with family name or teacher, which is regarded as mistakes in address forms. In order to avoid the embarrassing situation, teachers should develop students' 
pragmatic competence and awaken their awareness of pragmatics in the process of speaking English.

To begin with, our teachers are supposed to input real English materials by means of multimedia teaching. It is well known that language input is vital for foreign language learners. In twenty-first century, advanced science and technology has been applied in the field of education, which provides teachers with the teaching means to create the real foreign language context. Concerning address forms, it is proper foreign language learners to watch the videos with many English address forms, such as the movies, talk shows, feature films and special reports. The foreign language learners are required to observe the accurate way of address forms and the different address forms applied in various contexts rather than focusing on the surface of watching the videos. Also, practice makes perfect. It is necessary for students to imitate and practise the address forms in the context approximating the native language in the end of the videos. Only in this way can it reduce the mistakes made by the foreign language learners and lay the foundation of learning foreign language accurately for their future study and work.

Besides, the foreign language teachers are required to apply the task-based teaching method to the class, considering different individuals. Actually, the task-based teaching method focuses on the language learners and cultivates learners' ability of foreign language communication. The task-based teaching method sees concrete task as the carrier and finishing task, a driving force, which attaches the importance to developing and improving language skills in the process of accomplishing the tasks. The purpose of the teaching method is to use the foreign language in the process of learning language with the feature that communicative competence of foreign language comes first. Therefore, the task-based teaching method helps learners develop and improve their pragmatic competence. Practically, the foreign language teachers need to offer the real problems occurred in the daily life by means of tasks and improve learners' pragmatic competence.

Additionally, the foreign language teachers should enhance learners' sensitiveness of cultural difference which contributes to the differences of address forms between Chinese and English. Americans, influenced deeply by Christian, focus on the principle that everyone is equal in front of God, which is the reason why there is few terms of respect in English and children can call their parents and grandparents directly without terms of respect. By contrast, Chinese customs are affected by Confucian culture which regards the hierarchy as the core of moral principles. Therefore, filial piety is the key for people in their daily life and the younger generation are supposed to respect the elder, which is the source of the various terms of respect on address forms in Chinese. Therefore, it is necessary to offer courses on English culture, such as local conditions and customs, habits and customs and social taboos, and place stress on practicality to enhance learners' sensitiveness of cultural difference in case of misunderstandings arising from different address forms between Chinese and English.

\section{CONCLUSION}

Address forms, being a common phenomenon in communication, are important tools for establishing, maintaining and negotiating interpersonal relationships and the effect of verbal humor is aroused by pragmatic ambiguity created by the mismatch of address form and their intended referents in the physical surroundings. Therefore, the correct understanding of verbal humor must take the context into consideration and address forms should be focused on from pragmatic ambiguity perspective. On the perspective of teaching implication, foreign language teachers are required to accumulate the knowledge of the various forms of addressing employed in different countries as much as possible and enhance learners' sensitiveness of cultural difference which contributes to the differences of address forms between Chinese and English in the hope that the learners can acquire pragmatic competence and lay the foundation of learning foreign language accurately for their future study and work.

\section{REFERENCES}

[1] Attardo, S. Linguistic Theories of Humor [M].Berlin: Mouton de Gruyter, 1994

[2] Levinson, S. Pragmatics [M]. Cambridge: Cambridge University Press, 2001

[3] Braum, F. Terms of Address [M]. Berlin: Mouton de Gruyter, 1988

[4] Palmer, J. Taking Humor Seriously [M]. London: Routledge \& Kegan Paul, 1994

[5] Ruch, W. The Sense of Humor [M]. Berlin; New York: Mouton de Gruyter, 1998

[6] Yule, G. Pragmatics [M]. Shanghai: Shanghai Foreign Language Education Press, 2000

[7] Scollor, W. \& R. Scollon. Intercultural communication-A Discourse Approach, Oxford: Blackwell, 1996 